\title{
The effects of consumer freezing of food on its use-by date
}

Area of research interest: Foodborne pathogens

Study duration: 2020-08-01

Project status: Completed

Authors: Jessica Cairo, lulia Gherman and Paul Cook

DOI: https://doi.org/10.46756/sci.fsa.ret874

In the UK, food business operators are responsible for setting the safe shelf-life of a food which, in practice, should take into consideration the consumer habits, as well as factors affecting shelflife, such as food product characteristics, food processing techniques, transport, retail and domestic food storage temperatures, and type of packaging. Some countries specifically recommend including safety margins within shelf lives. There is no legal requirement in the UK to add a safety margin when setting shelf-life. According to regulations, food should be safe to eat on the use-by date.

According to UK regulations, pathogens should not be present in sufficient levels to cause foodborne illness on the use-by date, given food should still be safe to eat on that day. Assuming these requirements are met, this review considers the risks from the processes of consumer freezing, thawing and then refrigerated storage of food for 24 hours. These processes have the potential to increase pathogen levels. In this review, it was found that growth of some pathogens during refrigerated storage is a possibility, although the impact of freezing and thawing is not always well understood. This risk relates specifically to ready-to-eat foods as cooking of nonready-to-eat foods after defrosting eliminates pathogens.

Overall, there was little evidence to suggest a significant change in risk between consumers freezing food on the use-by date compared to freezing the food on the day before the use-by date. An area that needs further research is the potential for growth of $L$. monocytogenes after defrosting. More information on how food business operators set shelf-life and the extent of the safety margin would also be valuable.

Research report

PDF

View The effects of consumer freezing of food on its use-by date as PDF(Open in a new window) (678.89 KB) 